\title{
Breve Cotejo sobre o Papel do Ombudsman da Saúde Norueguês e a Atuação do Ministério Público em Defesa do Direito à Saúde no Brasil
}

\author{
SHORT CONSIDERATIONS ON THE ROLE OF NORWAY HEALTH \\ OMBUDSMAN AND THE DEFENSE OF THE RIGHT TO HEALTH BY THE \\ PROSECUTING COUNSEL IN BRAZIL
}

Geisa de Assis Rodrigues"

\section{RESUMO}

O artigo apresenta um paralelo entre o sistema de ombudsman da saúde da Noruega e a atuação do Ministério Público brasileiro, no que concerne à defesa do direito à saúde dos cidadãos. Para tanto, apresenta-se a opção do constituinte brasileiro de atribuir funções de ombudsman ao Ministério Público; em seguida, a forma de atuação desta instituição no Brasil, e, por fim, a comparação entre as características mais significativas das duas instituições.

\section{Palavras-Chave}

Direito à Saúde; Brasil; Ministério Público; Noruega.

\section{ABSTRACT}

This article presents a current parallel between patient ombudsman system in Norway and the role of the Brazilian Prosecuting Counsel, regarding the right to health. It is shown how the Brazilian legislative has opted to attribute ombudsman functions to the Prosecuting Counsel. Then it is pre-

(*) Professora licenciada da Universidade Federal da Bahia. Procuradora Regional da República. Atuou em defesa do direito à saúde na Procuradoria da República do Rio de Janeiro e na Procuradoria da República na Bahia. E-mail: <geisarodrigues@uol.com.br>. Recebido em 2.4.07. Aprovado em 6.6.07. 
sented the ways of action of this institution in Brazil and, finally, a comparison between the most important differences of these two institutions.

\section{Key words}

Brazil; Norway; Prosecuting Counsel; Right to Health.

\section{CONSIDERAÇÕES INICIAIS}

Apesar das imensas diferenças entre o Brasil e a Noruega(1), que vão desde elementos físicos como a dimensão territorial, o número de habitantes, o clima e a geografia, até aspectos socioculturais como a formação histórica do povo, o desenvolvimento econômico e as tradições culturais, temos como um importante ponto de interseção entre realidades tão díspares o reconhecimento pela ordem jurídica da existência de um direito à saúde do cidadão. Na verdade, seja na Noruega ou no Brasil, existe o consenso de que o exercício pleno da dignidade da pessoa humana pressupõe a prevenção de doenças e agravos à saúde e a promoção de ações de tratamento do bem-estar físico e mental debilitado.

Além da estruturação de ações de saúde do Estado e do controle das ações privadas na prestação de serviços de saúde, já se identificou a importante contribuição de instituições que aperfeiçoam os mecanismos de controle dos cidadãos sobre estas atribuições públicas. A existência de um ombudsman do paciente na Noruega denota a maturidade de um sistema que reconhece que falhas e equivocos na prestação dos serviços de saúde devem ser combatidos de todas as formas, pois os riscos enfrentados no exercício dessa atividade podem ser literalmente fatais, mesmo já atendendo de forma bastante razoável os interesses de seus usuários. Também traduz um enorme apreço pelo exercício democrático das funções públicas, posto que destaca a condição de cidadão do paciente, situação esta que nunca deve ser olvidada pelas autoridades responsáveis pelos encargos sanitários.

Não por acaso, a consolidação do Sistema Único de Saúde no Brasil e a própria afirmação constitucional do Estado Democrático de Direito, desde 1988, apresentaram desafios ao Ministério Público relativos à tutela dos di-

(1) As informações sobre a Noruega foram extraídas basicamente dos textos de Geir Sverre Braut (Trade-off between protective needs of society and individual rights in health legislation - examples from Norway") e de Olav Molven (The patiente ombudsman - the norwegian experience) ambos publicados neste número da Revista de Direito Sanitário. 
reitos dos pacientes, tornando-se paulatinamente tarefas prioritárias da instituição, uma vez que o exercício do direito à saúde, em nosso país, ainda está muito longe da realidade norueguesa.

O objetivo principal do presente artigo é apresentar algumas reflexões sobre como atua o ombudsman do paciente na Noruega e o Ministério Público no Brasil, para que possamos, deste breve cotejo, sobretudo, vivenciar criticamente a nossa instituição, aprendendo e ensinando em um diálogo rico para todos.

\section{ANOTAÇÕES SOBRE O DIREITO Ȧ SAÚDE NO BRASIL}

Na Constituição Brasileira de 1988, o direito à saúde é afirmado como um direito social(2) e considerado um "direito de todos e dever do Estado, garantido mediante políticas sociais e econômicas que visem à redução do risco de doença e de outros agravos e ao acesso universal e igualitário às ações e serviços para sua promoção, proteção e recuperação."(3)

Também foi a Constituição que instituiu o Sistema Único de Saúde (SUS) que congregou todos os serviços públicos de saúde, sejam executados diretamente pela administração pública, através de equipamentos e recursos humanos próprios, ou através da contratação de instituições privadas. ${ }^{(4)}$

(2) Art. 6 São direitos sociais a educação, a saúde, o trabalho, a moradia, o lazer, a segurança, a previdência social, a proteção à maternidade e à infância, a assistência aos desamparados, na forma desta Constituição.

(3) Art. 196 da CF. Na Lei n. 8.080/90 o direito à saúde é minudenciado: "Art. 2‥ A saúde é um direito fundamental do ser humano, devendo o Estado prover as condições indispensáveis ao seu pleno exercício. $\S 1^{\circ} \mathrm{O}$ dever do Estado de garantir a saúde consiste na formulação e execução de políticas econômicas e sociais que visem à redução de riscos de doenças e de outros agravos e no estabelecimento de condições que assegurem acesso universal e igualitário às ações e aos serviços para a sua promoção, proteção e recuperação. $\S 2^{\circ} 0$ dever do Estado não exclui o das pessoas, da família, das empresas e da sociedade. Lei n. 8.080/90: Art. $3^{\circ} A$ saúde tem como fatores determinantes e condicionantes, entre outros, a alimentação, a moradia, o saneamento básico, o meio ambiente, o trabalho, a renda, a educação, o transporte, o lazer e o acesso aos bens e serviços essenciais; os níveis de saúde da população expressam a organização social e econômica do País. Parágrafo único. Dizem respeito também à saúde, as ações que por força do disposto no artigo anterior se destinam a garantir às pessoas e à coletividade condições de bem-estar físico, mental e social."

(4) Art. 198 da CF: As ações e serviços públicos de saúde integram uma rede regionalizada e hierarquizada e constituem um sistema único, organizado de acordo com as seguintes diretrizes: 1 - descentralização, com direção única em cada esfera de governo; 11 - atendimento integral, com prioridade para as atividades preventivas, sem prejuizo do serviços assistenciais; III - participação da comunidade. 
O SUS tem como maior meta concretizar o direito de saúde dos cidadãos brasileiros, mediante a implementação de políticas públicas de prevenção e tratamento das doenças e agravos à saúde.

No atual sistema brasileiro de atendimento universal, todos são titulares do direito à saúde, embora existam grupos de pessoas que têm sua saúde especialmente protegida pelo governo, como crianças e adolescentes, idosos, portadores de deficiência e comunidades indígenas. Anteriormente faziam jus ao atendimento de saúde os filiados à previdência pública, através de uma contraprestação específica. A universalidade implicou um salto de 30 milhões de beneficiários-segurados para uma população de 150 milhões de cidadãos com estes direitos.

As três instâncias da peculiar Federação brasileira, União Federal, Estados e Municípios têm responsabilidades na implementação do direito à saúde, sendo que incumbe aos Municípios, prioritariamente, a execução dos serviços públicos de saúde, incluindo as atividades assistenciais, de vigilância epidemiológica e de vigilância sanitária; aos Estados cabe a coordenação dos serviços públicos de saúde e a execução dos serviços em caráter complementar, inclusive prestando apoio técnico e financeiro aos Municípios; e à União Federal, a coordenação geral do sistema, a formulação das políticas públicas de âmbito nacional, a fiscalização do cumprimento de suas metas e de seu financiamento, dentre outras atribuições de estruturação do Sistema Único de Saúde ${ }^{(5)}$.

No Brasil, ao contrário da Noruega, em que uma ínfima parte dos serviços públicos de saúde são prestados por instituições privadas, o Sistema Único de Saúde convive com uma significativa rede de prestadores de serviço de saúde de natureza particular. Existem empresas que administram os Planos Privados de Assistência à Saúde, que funcionam como uma espécie de seguro, no qual os associados contribuem mensalmente para obterem o acesso a uma rede de profissionais, hospitais, clínicas e serviços credenciados pela operadora do plano. ${ }^{(6)}$ Há inclusive uma agência reguladora federal, denominada Agência Nacional de Saúde Suplementar ${ }^{(7)}$, que fiscaliza o setor.

Além do fato do direto da saúde ser constitucionalmente previsto, o Código de Defesa do Consumidor ${ }^{(8)}$ garante ao usuário do serviço de saúde, seja de natureza púbica ou privada, a sua qualidade. Tem o paciente, portanto, direito a um serviço adequado as suas necessidades. Quando há lesão

(5) A Lei n. 8.080/90, conhecida como a Lei Orgânica da Saúde, disciplina o exercício dessas atribuições.

(6) A Lei n. 9.656/98 regulamenta o setor.

(7) A Lei n. 9.961/00 criou tal agência.

(8) A Lei n. 8.078/90 disciplina os direitos e deveres dos sujeitos da relação de consumo de bens e serviços. 
do direito do paciente pelo Estado, mesmo quando prestado por instituição privada delegatária, a responsabilidade é objetiva, bastando que se configure o nexo de causalidade entre a ação ou omissão pública na prestação do serviço de saúde e o dano causado. No caso dos serviços privados exige-se a demonstração da culpa.

A exemplo do que existe na Noruega, a decisão livre do paciente sobre a execução de práticas diagnósticas ou terapêuticas também deve ser respeitada, ressalvados os casos de impossibilidade da manifestação da vontade, como na urgência médica ou na incapacidade do doente, quando se transfere para a sua família o consentimento. A Lei n. 10.216/2001 estabelece os requisitos para a internação compulsória do paciente com transtorno mental, sendo esta a última opção, que deve ser devidamente justificada e sujeita ao controle do Ministério Público .

Há uma crescente preocupação sobre como compatibilizar a proteção da saúde pública e os direitos individuais dos pacientes nos casos de doenças infecto-contagiosas e outros agravos à saúde que necessitam de restrição de direitos, sobretudo diante das novas formas de contaminação potencializadas pela globalização econômica.

Não existe uma legislação brasileira específica sobre o tema, uma vez que a lei de vigilância epidemiológica é de 1975 e a lei de infrações sanitárias de $1977^{(9)}$. Assim, não temos uma regulamentação adequada aos valores e princípios albergados na Constituição Federal de 1988 dos instrumentos de restrição de direitos como a quarentena, o isolamento, o tratamento compulsório, a busca ativa de contatos, observação do suspeito de estar infectado e medidas de restrição de circulação de pessoas, dentre outras. É certo que o Brasil é membro da Organização Mundial de Saúde (OMS) e já cumpre disposições do Regulamento Sanitáro Internacional, que prevê tais medidas restritivas para garantir a segurança sanitária internacional, embora este ainda esteja em processo de internalização no direito brasileiro(10). De qualquer sorte, o sistema jurídico brasileiro autoriza limitações aos direitos - individuais em favor do interesse público de resguardar as condições sanitárias da população, o que ocorreu, por exemplo, no episódio do combate à Síndrome Respiratória Aguda Grave (SARS); mas, tão-somente na razão e na proporção necessária para que este fim seja alcançado.

A existência da proteção jurídica do direito à saúde não torna menos problemática a sua efetividade no Brasil. Há um real descompasso entre a

(9) Respectivamente a Lei n. $6.259 / 75$ e a Lei n. $6.437 / 77$.

(10) Está em trâmite na Câmara dos Deputados o PDC n. 27/07 para a edição do decreto legislativo que introduz em nosso ordenamento jurídico o Regulamento Sanitário Internacional aprovado em 25 de maio de 2005, muito embora as autoridades sanitárias brasileiras já o venham aplicando. 
garantia formal do direito à saúde e sua implementação concreta. Com efeito, este direito reclama o investimento de recursos públicos que nem sempre estão disponiveis na medida necessária. Muito embora já tenhamos avançado bastante, pois segundo a justificativa da Portaria n. 399 do Gabinete do Ministro (GM) de fevereiro de 2006: "o SUS tem uma rede de mais de 63 mil unidades ambulatoriais e de cerca de 6 mil unidades hospitalares, com mais de 440 mil leitos. Sua produção anual é aproximadamente de $12 \mathrm{mi}$ Ihões de internações hospitalares; 1 bilhão de procedimentos de atenção primária à saúde; 150 milhões de consultas médicas; 2 milhões de partos; 300 milhões de exames laboratoriais; 132 milhões de atendimentos de alta complexidade e 14 mil transplantes de órgãos"; há ainda muito por fazer.

Para garantir a universalidade do atendimento de saúde existem vários dispositivos na Constituição e nas leis de regência, mormente as Leis ns. 8.080/90 e 8.142/90, e, mais recentemente, na Emenda Constitucional n. 29, de 2000 prevendo investimentos mínimos na saúde. A União Federal deve destinar verbas para a saúde de acordo com o crescimento do Produto Interno Bruto, os Estados devem aplicar um percentual mínimo de $12 \%$ do produto da arrecadação dos impostos e os Municípios e o Distrito Federal devem destinar um percentual de $15 \%{ }^{(11)}$. Embora esta, ainda, não seja uma realidade em todos os rincões do país, a vinculação dos gestores a uma meta já vem representando importantes aportes de recursos para a área de saúde. Ademais, estes recursos são destinados a contas especiais, os denominados fundos de saúde, de cada instância administrativa, de modo a garantir o efetivo dispêndio dos valores em ações e serviços de saúde.

A questão do financiamento público desta área é bastante tormentosa porque as necessidades dos cidadãos por medicamentos, terapias e meios de diagnósticos têm um crescimento exponencial em descompasso com o orçamento público. Tal quadro é intensificado pela ênfase da medicina contemporânea no tratamento das doenças e no culto aos medicamentos, cada vez mais caros como atesta o sucesso da bilionária indústria farmacêutica.

Infelizmente, o Brasil ainda tem que lidar com os atos de corrupção dos valores destinados à saúde em pleno século XXI, como no esquema envolvendo o desvio de verbas destinadas à compra de ambulâncias, investigado na operação sanguessuga. É, portanto, de fazer invejar a qualquer brasileiro a afirmação do professor Olav Molven de que os cidadãos da Noruega tradicionalmente pensam que as autoridades públicas agem em seu favor e nelas confiam ${ }^{(12)}$.

(11) Por determinação da emenda n. 29/00.

(12) Literalmente o autor diz: "thoug citizens in Norway traditionally think public authorities act on behalf of them, and to a high degree, at least compared with many other countries have confidence in them." 
Um outro enorme desafio ao exercício do direito à saúde no Brasil é a garantia da efetiva igualdade dos cidadãos ao acesso aos serviços de saúde. Os contrastes que caracterizam a sociedade brasileira se manifestam de forma dramática na proteção da saúde. Enquanto alguns têm acesso a serviços médicos de altíssimo nível, comparáveis aos de qualquer país desenvolvido, outros agonizam em filas de atendimento, desprovidos de uma assistência mínima. A parcela mais rica da sociedade, sobretudo nas grandes cidades, não utiliza ordinariamente os serviços públicos de saúde, ressalvados alguns programas de imunização, o tratamento contra a AIDS, procedimentos médicos de maior complexidade e atendimentos de emergência. Não compartilham das agruras ainda típicas do sistema, como insuficiência de leitos, de medicamentos, de equipamentos de diagnóstico, de assistência de profissionais de saúde, da concentração de atendimentos em determinadas regiões do país, o que esgarça bastante o tecido social e faz com que aqueles politicamente mais fortes não se comprometam com os destinos do sistema.

Por outro lado, as notórias limitações do Estado em atender o direito à saúde de todos os cidadãos brasileiros realçam também o papel dos prestadores de serviços de saúde privados, sejam operadores de plano de saúde, hospitais, clínicas ou profissionais, que são também obrigados a respeitar os direitos dos pacientes, posto que no fundo a saúde da população é um interesse essencialmente coletivo. É nesse quadro desafiante que as instituições que velam pelo efetivo exercício do direito à saúde no Brasil têm que exercer as suas atribuições.

\section{A OPÇÃO DO CONSTITUINTE DE 1988 PELA ATRIBUIÇÃO DAS FUNÇÕES DE OMBUDSMAN AO MINISTÉRIO PÚBLICO'(13)}

Tem sido comum nos processos de redemocratização mais recentes a discussão sobre a criação de instituições destinadas primordialmente à defesa dos interesses da sociedade, especialmente em face de violações perpetradas pelo Poder Público, nos moldes do ombudsman sueco, a exemplo do que ocorreu na Espanha e em Portugal(14). Surgido na Suécia há quase

(13) Parte deste item é resultado da revisão de considerações já tecidas em nosso livro "Ação civil pública e termo de ajustamento de conduta. Rio de Janeiro: Forense, 2006.

(14) A Constituição espanhola em seu art. 54 prevê a figura do defensor do povo: "Uma lei orgânica regulará a instituição do Defensor do Povo como alto-comissário das Cortes gerais, por estas designado para a defesa dos direitos compreendidos neste título e que, para esse efeito, poderá supervisionar a atividade da Administração, dando conta às Cortes Gerais." A Constituição portuguesa institui em seu art. 23 a figura do Provedor de Justiça: "1. Os cidadãos podem apresentar queixas por 
dois séculos ${ }^{(15)}$, o ombusdman tem no controle da função administrativa do Estado seu campo de atuação originário, muito embora inicialmente também realizasse o controle político da orientação administrativa do governo(16). Nasce como uma Instituição independente do Poder Executivo; mas, ligada ao Parlamento, atuando extrajudicialmente para dar respostas às reclamações dos cidadãos contra a ineficiente prestação de serviços públicos ou a adoção de práticas administrativas incompativeis com o interesse público. Nesta concepção primeva, o ombudsman apenas atua na esfera não jurisdicional e suas deliberações não vinculam o Poder Público; todavia, já conta com poderes de requisição de informações e oitiva de pessoas para que possa instruir suas investigações.

Mais recentemente vivemos o fenômeno da multiplicação de ombudsman, tanto espacial, uma vez que vários são os países que passaram a adotar a Instituição, quanto material, pois a esfera de atuação do ombudsman se ampliou significativamente para abranger relações de consumo, liberdade econômica, imprensa, serviços bancários, saúde etc. Assim, "the grievance man" tem como função examinar as querelas contra sujeitos públicos e privados e apresentar uma forma de solução de controvérsia alternativa, mais rápida, econômica e facilmente acessível. Ademais, já se admi-

ações ou omissões dos poderes públicos ao Provedor de Justiça, que as apreciará sem poder decisório, dirigindo aos órgãos competentes as recomendações necessárias para prevenir e reparar injustiças. 2. A atividade do Provedor de Justiça é independente dos meios graciosos e contenciosos previstos na Constituição e nas leis. 3. O Provedor de Justiça é um órgão independente, sendo o seu titular designado pela Assembléia da República. 4. Os órgãos e agentes da Administração Pública cooperam com o Provedor de Justiça na realização de sua missão."

(15) Constituição sueca de 1809 "Art. 96. O Parlamento designará pelo menos dois cidadãos de reconhecida competência legal e marcante integridade para supervisionar, na condição de ombudsman do parlamento, de acordo com as diretrizes por este estabelecidas, a observância das leis e regulamentos por todos os funcionários e empregados; e instaurar processos, perante os Tribunais próprios, contra os que, no exercicio de suas funções públicas, praticarem ato ilicito mediante parcialidade ou favoritismo, ou de outra forma, ou se omitirem no cumprimento do dever. $O$ ombudsman estará sujeito sob todos os aspectos às mesmas responsabilidades estabelecidas para os promotores públicos pela lei civil e penal, e pelas regras do processo judicial atinente a promotores. O parlamento designará o número necessário de substitutos do Ombudsman, que deverão ter as mesmas qualificações dele." LEITE, Celso Barroso. Ombudsman. Corregedor administrativo. A instituição escandinava que o mundo vem adotando. Rio de Janeiro: Zahar, 1975, p. 35.

(16) Segundo a história constitucional sueca inicialmente foi uma resposta à necessidade de sindicância parlamentar sobre a ação régia no campo administrativo. Com o governo parlamentar, sua atuação foi se restringindo aos casos em que houvesse disfunção objetiva, passando, assim, a ser o tutor público do uso correto do poder administrativo. Vide verbete ombudsman da lavra de Giuseppe de Vergottini, no Brasília: Ed. da UNB, 1991, v. 2, p. 831-842. 
te que suas decisões sejam imperativas ou, eventualmente, que possa postular em juízo em favor do reclamante. O ombudsman com ou sem poder decisório vinculante exerce um importante papel na solução extrajudicial dos conflitos, atuando como mediador entre as partes. A sua atuação mais intensa é na composição de litígios individuais; mas, é comum que ao detectar a incidência social do conflito o ombudsman expeça recomendações de caráter mais genérico, ou proponha alterações legislativas que possam erradicar o conflito transindividual.

$\mathrm{Na}$ verdade, consideramos que o traço mais marcante da previsão normativa de uma instituição análoga ao ombudsman é que a sua mera existência simboliza a possibilidade do efetivo exercício da cidadania, pois traduz a mensagem que o controle dos atos da Administração Pública está ao alcance de qualquer um do povo. Sem querer ser simplista, sabemos que ao lado de inúmeros outros fatores de natureza econômica, social e política, a experiência secular do ombudsman contribuiu para a sólida vivência democrática nos paises que o souberam cultivar ${ }^{(17)}$.

O anseio por essa estabilidade democrática com certeza motivou que muitos atores do último processo constituinte brasileiro defendessem a existência da criação de uma instituição nos moldes do ombudsman no cenário jurídico pátrio. Houve um dissenso entre os que consideravam necessária a concepção de uma nova instituição, com funções de defesa dos interesses da sociedade(18), e os que entendiam ser melhor reservar ao Ministério Público essas novas atribuições ${ }^{(19)}$. Para estes últimos as funções de defesa da

(17) O sueco Hans Blix lembra que, por vezes, se indaga se essa instituição não é mais útil num moderno Estado de bem-estar, como o seu pais. Mas, ele próprio responde que a Suécia do século XIX estava ainda bem longe de ser o que é hoje e, todavia, "então como agora o corregedor administrativo era um mecanismo de grande utilidade." Apud Celso Barroso Leite, op. cit., p. 47.

(18) Nesse sentido TÁCITO, Caio. Ombusdman: o defensor do povo. Revista de Direito Administrativo, Rio de Janeiro, n. 171, p. 15-26, jan./mar. 1988, OLIVEIRA FILHO, João de. O ombusdman, instrumento de defesa dos direitos humanos nas democracias modernas. Revista dos Tribunais, São Paulo, v. 497, mar. 1977. Também a Comissão de Notáveis que elaborou um anteprojeto de Constituição no seu art. 56, defendia a instituição do "Defensor do Povo", a fim de "zelar pelo efetivo respeito dos poderes do Estado aos direitos assegurados nesta Constituição, apurando abusos e omissões de qualquer autoridade e indicando aos órgãos competentes as medidas necessárias à sua correção ou punição", o qual seria escolhido pela maioria absoluta dos deputados federais (ou estaduais nos Estados) e gozando das mesmas prerrogativas de parlamentares e vencimentos dos ministros do STF.

(19) Com esse entendimento Diogo Figueiredo Moreira Neto, op., cit. p. 95: "Não obstante a popularidade da instituição e o êxito que possa ter alcançado em outros paises, entendemos que, entre nós, suas funções devem ser cometidas, com maior eficácia, ao Ministério Público. Este órgão, não só em razão de sua tradição e da presença difundida em todo o território nacional, abrangendo todos os niveis hierárquicos de provocação, soma a experiência profissional ao preparo funcional (concur- 
cidadania seriam um aprofundamento natural da clássica vocação da instituição de defesa do ordenamento jurídico, uma verdadeira releitura do encargo de proteção dos fracos e da salvaguarda do bem público, bem como uma forma de aproveitar a capilaridade da instituição em um país continental(20). Todavia, o que restava evidente era a necessidade de superar a dependência da instituição em relação ao Poder Executivo(21) e romper com o seu histórico modo de atuar, ainda muito limitado pelas peias do individualismo e praticamente se resumindo ao oficiar perante o juízo.

so público) e a independência da ação à vocação de defesa do interesse indisponível, razões pelas quais entendemos supérflua, em nosso sistema de controle de poder, a instituição de um "ombudsman", ou que denominação assuma com competência paralela e repetitiva, se não competitiva com o Ministério Público." Também Fábio Konder Comparato que no projeto que elaborou de Constituição previa em seu art. 186 - Ministério Público com atribuições de ombudsman. MUDA Brasil. Uma Constituição para o desenvolvimento democrático. São Paulo: Brasiliense, 1987. Júlio Aurélio Vianna Lopes em importante trabalho sobre o Ministério Público relembra que: "A corporação do Ministério Público se opôs à criação do "Defensor do povo", posição consignada em seu VI Congresso Nacional, argumentando que a instituição já cumpria esta função nas pequenas cidades do interior, devendo ser aperfeiçoada para as grandes cidades...A influência dos "Plenários Pró-Participação popular" foi evidente nas várias proposições de sua lavra que se converteram em relações constitucionais, devendo ser observado que foram os pioneiros na atribuição da função de zelador dos direitos dos cidadãos pelos Poderes Constituidos - diç̧ão típica da proposta de "Defensor do Povo" (tal como se configurou no Projeto dos "notáveis") - ao Ministério Público. É importante salientar, ainda, que o Parquet sempre constou de seus anteprojetos no tema "Participação popular", o qual era, explicitamente, um dos eixos que norteavam a discussão entre os participantes dos movimentos, ao lado de outros - LOPES, Júlio Aurélio Vianna. 'Funções do Estado', 'Alicerces da sociedade', e 'Condições da vida". Rio de Janeiro: Lumen Juris, 2000. p. 111-113.

(20) Como a pioneira opinião de Roberto Lyra: "Assim, o. Ministério Público evoluirá para um ministério social que assumirá a responsabilidade da tentativa da ordem juridica em todo o mundo - a paz social pela justiça social, tarefa máxima da democracia na atual conjuntura da humanidade ... Um ministério social promoverá a justiça social, curará dela e não só de uma justiça pública, estatal, oficial. A ordem juridica será adaptada aos dramas contemporâneos." (LYRA, Roberto. Visão social do direito. Rio de Janeiro: Ed. Rio, 1976. p. 57.)

(21) Cf. Fábio Konder Comparato: "O necessário complemento de uma reforma do Judiciário consiste na reformulação das funções do Ministério Público. Este último tem sido, até hoje, um auxiliar do estado, quando deveria ser, exclusivamente, um defensor da sociedade civil. A distinção aqui se impõe vigorosamente: o Estado o corpo de seus procuradores, encarregados de representar judicialmente os seus interesses. Não pode ser esta a função do Ministério Público. Os seus membros devem atuar, como se repete nos manuais doutrinários e arrazoados forenses, no interesse da sociedade. Apenas deixa-se de tirar a necessária conclusão dessas premissas, qual seja, a autonomia do Ministério Público em relação ao Executivo." COMPARATO, Fábio Konder. Segurança e democracia. In: Direito, cidadania e participação. São Paulo: T. A. Queiroz, 1981. p. 223. 
O Ministério Público que emerge da nova ordem constitucional é uma instituição diferente, com novas atribuições, com importantes garantias institucionais e pessoais, aliando a sua histórica tradição de postulação em juízo, seja no âmbito penal seja no âmbito cível na tutela de direitos transindividuais e individuais indisponiveis, com a possibilidade de uma ampla atuação de defesa extrajudicial da cidadania e com os poderes de investigação e de utilizar outras medidas extrajudiciais para a defesa do patrimônio público e social. Assim, o Ministério Público brasileiro é uma instituição bastante singular se comparada com os seus congêneres estrangeiros, principalmente em virtude de sua independência e de seu novo rol de atribuições, com a exclusividade da ação penal pública, a defesa judicial dos direitos transindividuais na esfera cível e o exercício de suas funções de ombudsman.

Por exemplo, no Ministério Público Federal a defesa de direitos constitucionais ${ }^{(22)}$ passou a ser exercida pelos Procuradores dos Direitos do Cidadão, integrada pelo Procurador Federal dos Direitos do Cidadão, um Subprocurador-Geral indicado pelo Procurador-Geral da República, após prévia aprovação do Conselho Superior do Ministério Público Federal, e pelos Procuradores Regionais do Direito do Cidadão em cada Estado, também nomeados pelo Procurador Geral(23). A Procuradoria Federal dos Direitos do

(22) A Lei Complementar n. 75/93 estabelece o seguinte a respeito da defesa dos direitos constitucionais: "Art. 11. A defesa dos direitos constitucionais do cidadão visa à garantia do seu efetivo respeito pelos Poderes Públicos e pelos prestadores de serviços de relevância pública. Art. 12. O Procurador dos Direitos do Cidadão agirá de ofício ou mediante representação, notificando a autoridade questionada para que preste informação, no prazo que assinar. Art. 13. Recebidas ou não as informações e instruído o caso, se o Procurador dos Direitos do Cidadão concluir que direitos constitucionais foram ou estão sendo desrespeitados, deverá notificar o responsável para que tome as providências necessárias a prevenir a repetição ou que determine a cessação do desrespeito verificado. Art. 14. Não atendida, no prazo devido, a notificação prevista no artigo anterior, a Procuradoria dos Direitos do Cidadão representará ao poder ou autoridade competente para promover a responsabilidade pela ação ou omissão inconstitucionais. Art. 15. É vedado aos órgãos de defesa dos direitos constitucionais do cidadão promover em juizo a defesa de direitos individuais lesados. $\S 1^{\circ}$ Quando a legitimidade para a ação decorrente da inobservância da Constituição Federal, verificada pela Procuradoria, couber a outro órgão do Ministério Público, os elementos de informação ser-lhe-ão remetidos. $\S 2^{\circ}$ Sempre que o titular do direito lesado não puder constituir advogado e a ação cabivel não incumbir ao Ministério Público, o caso, com os elementos colhidos, será encaminhado à Defensoria Pública competente. Art. 16. A lei regulará os procedimentos da atuação do Ministério Público na defesa dos direitos constitucionais do cidadão."

(23) A Lei Complementar n. 75/93 assim dispõe: "Art. 40. O Procurador-Geral da República designará, dentre os Subprocuradores-Gerais da República e mediante prévia aprovação do nome pelo Conselho Superior, o Procurador Federal dos Direitos do Cidadão, para exercer as funções do ofício, pelo prazo de dois anos, permitida uma recondução, precedida de nova decisão do Conselho Superior. $\S 10$ Sempre que possivel, o Procurador não acumulará o exercício de suas funções com outras do 
Cidadão realiza a coordenação e a revisão da atuação dos Procuradores na defesa da cidadania, exercendo, dentre outras funções, a apreciação do arquivamento dos procedimentos administrativos e inquéritos civis vinculados a sua área. A Procuradoria dos Direitos do Cidadão exerce especialmente as importantes atribuições de ombudsman que foram atribuídas ao. Ministério Público, porque mesmo em situações em que o Ministério Público Federal não pode ajuizar pleitos, as demandas dos cidadãos podem ser examinadas administrativamente.

É importante ressaltar que a opção do constituinte foi conferir ao Ministério Público as atribuições clássicas do ombudsman ao invés de criar uma instituição como o Ombudsman civil da Noruega, ligado ao Parlamento e com uma incumbência para assuntos administrativos em geral. Não se impede que o Executivo crie ouvidorias e corregedorias para fiscalizar o cumprimento de seus serviços. Em matéria de saúde, a União Federal, e vários Estados brasileiros, como São Paulo, Santa Catarina e Mato Grosso, já possui ouvidorias de saúde, assim como alguns hospitais públicos e privados já contam com este canal de relacionamento entre os cidadãos-usuários e as instituições ${ }^{(24)}$. Também existem disque-saúde e mecanismos de acesso na internet para apresentar denúncias e reclamações. Mas, a des-

Ministério Público Federal. $\S 2^{\circ} \bigcirc$ Procurador somente será dispensado, antes do termo de sua investidura, por iniciativa do Procurador-Geral da República, anuindo a maioria absoluta do Conselho Superior. Art. 41. Em cada Estado e no Distrito Federal será designado, na forma do art. 49, III, órgão do Ministério Público Federal para exercer as funções do ofício de Procurador Regional dos Direitos do Cidadão. Parágrafo único. O Procurador Federal dos Direitos do Cidadão expedirá instruções para o exercício das funções dos ofícios de Procurador dos Direitos do Cidadão, respeitado o princípio da independência funcional." O primeiro Procurador Federal dos Direitos do Cidadão foi o Dr. Alvaro Augusto Ribeiro Costa.

(24) O acesso à Ouvidoria Nacional do Sistema Único de Saúde é <http:// portal.saude.gov.br/portal/saude/area.cfm?id_area=1003->; à do Estado de Santa Catarina é <http://www.saude.sc.gov.br/cidadao/ouvidoria/ouvidoria_oquee.htm>; Estado do Mato Grosso é <http://www.saude.mt.gov.br/site/ces/ouvidoria.php>; Estado de São Paulo é http://www.saude.sp.gov.br/portal/08a7bdd7c89b06a70174d93a48c84061.htm. Em relação à ouvidoria de São Paulo, José de Ambrosis Pinheiro Machado relata: "Na Saúde, existe uma malha de ouvidores locais, situada dentro das instituições e articulada com a Ouvidoria Central, que recebe os casos não solucionados no nível local. A ouvidoria central da Saúde, em 2003, recebeu 31.365 manifestações, das quais 50\% eram reclamações. Um exemplo da atuação da ouvidoria da Saúde foi a identificação de um problema que resultou no fechamento de uma maternidade que estava cobrando pela realização de partos. Além do hospital ser fechado, mais de 400 pessoas foram indenizadas pelos prejuizos sofridos. Outro caso importante foi o da ouvidoria do Centrinho - Hospital de Reabilitação de Anomalias Craniofaciais (Universidade de São Paulo - campus Bauru), que desenvolveu uma campanha de conscientização dos profissionais envolvidos para melhoria da caligrafia nos prontuários e receituários médicos." (artigo no http://www.abosaopaulo.org.br/biblioteca/artigo03.htm) 
peito da importância de tais órgãos de controle, a sua limitação a questões individuais e a relativa autonomia em relação às autoridades públicas às quais estão vinculadas, faz com que consideremos que o Ministério Púbico esteja mais próximo da figura do ombudsman por sua independência e o rol legal de seus poderes.

\section{FORMA DE ATUAÇÃO DO MINISTÉRIO PÚBLICO NA PROMOÇÃO DO DIREITO À SAÚDE}

O Ministério Público acompanha a estrutura federativa de nossa República no que se refere aos órgãos jurisdicionais, pois os Municípios não possuem Poder Judiciário. Assim, temos o Ministério Público da União, que se divide em Ministério Público Federal, Ministério Público Militar e Ministério Público do Trabalho; e o Ministério Público dos Estados. Os ramos do Ministério Público que exercem atribuições de promoção do direito à saúde de forma genérica são: Ministério Público Federal, quando há envolvimento de qualquer tipo de responsabilidade de entes e autoridades federais, e o Ministério Público dos Estados, em relação às demais questões. O Ministério Público do Trabalho exerce importantes atribuições no que se refere à saúde do trabalhador nas relações laborais e, por isto, não será referenciado em nosso trabalho.

Não há uniformidade de organização interna dentro dos ramos do Ministério Público na atuação em favor da saúde. Em alguns locais temos um ou alguns membros que se dedicam exclusivamente ao que se chama de ofício da saúde; em outras localidades, a tutela da saúde está ao encargo de quem realiza a defesa da cidadania em geral, concorrendo com outros tópicos como educação, proteção dos portadores de deficiência. E, em outros casos, o membro do Ministério Público realiza todas as suas atribuições de âmbito penal e civil, além da tutela da saúde ${ }^{(25)}$.

Existem basicamente as seguintes linhas de atuação do Ministério Público na defesa do direito à saúde : a) a repressão a fraudes de instituições públicas e privadas, prestadoras do serviço público de saúde; b) a repressão a atos de improbidade imputados a administradores públicos envolvendo as verbas públicas destinadas à saúde; c) a estruturação do SUS nas esferas Federal, estaduais e municipal, com a fiscalização da existência do serviço e de sua qualidade; da fiscalização da implementação das políticas públicas de saúde, como os programas de vacinação, de saúde da mulher, de

(25) Por exemplo, segundo o relatório da Procuradoria Federal dos Direitos do Cidadão do Ministério Público Federal do ano de 2005, apenas os Estados da Bahia, Goiás, Minas Gerais, Piauí, Rio de Janeiro e Rio Grande do Norte contavam com um ou mais Procuradores que oficiavam exclusivamente em matéria de saúde. 
transplante de órgãos etc.; e e) a promoção de direitos coletivos e individuais indisponiveis de crianças, adolescentes, idosos e portadores de transtornos mentais, em relação ao tratamento a eles dispensado.

$\mathrm{Na}$ defesa do direito à saúde, pode o Ministério Público adotar várias medidas, de natureza administrativa ou judicial, que quase sempre são precedidas de uma investigação, a qual se desenvolve através do inquérito civil público.

A instauração do inquérito pode ocorrer a partir de representação de qualquer pessoa, associação, pessoa jurídica de direito ou de direito privado, ou de ofício. Existem situações em que a lei determina que o Ministério Público exerça controle sobre determinada atividade, o que pode fazê-lo por intermédio do inquérito, como no caso da Lei n. 10.216/2001, que elenca a hipótese de intimação do Ministério Público Estadual quando se tratar de internação compulsória de portador de transtorno mental. A participação da sociedade tem sido relevante na provocação dos inquéritos civis, sendo considerada uma verdadeira forma de participação política mais ampla, mesmo porque não é necessário o status de eleitor para que se possa deflagrar a investigação. Para a instrução do inquérito, o Ministério Público conta com poderes de requisição de informações ${ }^{(26)}$, de convocação de pessoas para prestar depoimentos ${ }^{(27)}$, de requisição de serviços técnicos de órgãos

(26) $\bigcirc$ art. 26, inciso I, letra $b$, da Lei n. 8.625/93, ao tratar das funções do Ministério Público, determina que: "No exercício de suas funções o Ministério Público poderá: 1 - instaurar inquéritos civis e outras medidas e procedimentos administrativos pertinentes e, para instrui-los: b) requisitar informações, estaduais e municipais, bem como dos órgãos e entidades da administração direta, indireta ou fundacional, de qualquer dos Poderes da União, dos Estados, do Distrito Federal e dos Municipios." Por sua vez, a lei complementar n. 75/93 prevê em seu art. 8ㅇ, incisos II e IV: "Para o exercício de suas atribuições, o Ministério Público da União poderá nos procedimentos de sua competência: $\|$ - requisitar informações, exames, perícias e documentos de autoridades da Administração Pública direta ou indireta; IV - requisitar informações e documentos de entidades privadas. Com efeito, o poder de requisição já estava previsto no art. $8^{\circ}, \S 1^{\circ}$, da Lei n. $7.347 / 85$.

(27) Art. 26, I, alinea a da Lei n. 8.625/93: "No exercício de suas funções o Ministério Público poderá: 1 - instaurar inquéritos civis e outras medidas e procedimentos administrativos pertinentes e, para instruí-los: a) expedir notificações para colher depoimento ou esclarecimentos, e em caso de não comparecimento injustificado, requisitar condução coercitiva, inclusive pela Policia civil ou militar, ressalvadas as prerrogativas previstas em lei." A Lei Complementar n. 75/93 em seu art. 8ㅜ, inciso I dispõe: "Para o exercício de suas atribuições, o Ministério Público da União poderá nos procedimentos de sua competência: 1 - notificar testemunhas e requisitar sua condução coercitiva, no caso de ausência injustificada." Como anota Mazzilli: "Só em casos em que seja indispensável a oitiva da pessoa é que se deve valer da notificação formal com cominação de condução coercitiva, porque se trata de medida que importa grave restrição de direito de ir e vir, e, assim, deve ser imposta com cautela e extrema parcimônia." Op. cit. p. 166. 
públicos ${ }^{(28)}$, dentre outros. Esse arsenal de poderes é imprescindivel para que a investigação seja bem sucedida. Instruido o procedimento, cabe ao membro do Ministério Público eleger a medida mais adequada ao caso. Assim poderá propor ação civil pública, ação coletiva ou ação de improbidade, expedir recomendação, celebrar termo de ajustamento de conduta ou promover o arquivamento do inquérito civil.

O objetivo precípuo do inquérito civil é investigar a materialidade dos fatos potencialmente ou efetivamente lesivos ao direito à saúde, identificando os responsáveis pela sua prática. Este objeto é o mais amplo possível, podendo se referir a um fato determinado ou a um conjunto de fatos que revelem um estado de coisas contrário aos interesses da coletividade. 0 adjetivo civil qualifica a função do inquérito para investigar fatos da órbita não penal. Mas, nada impede que na apuração de um ilícito civil se constate indícios de materialidade e autoria de um delito penal, podendo os dados obtidos no inquérito civil servir como elemento para a propositura de uma ação penal. Tem natureza de procedimento administrativo de investigação e, por isso, não é obrigatório, ou seja, se houver elementos suficientes para a propositura de ação judicial (ação civil pública, ação de improbidade ou coletiva) não é necessário que tenha havido inquérito civil prévio.

$O$ inquérito civil se caracteriza pela nota do informalismo. Não existe um rito a ser observado na condução dessa investigação, embora deva ser sempre escrita, reduzindo as atividades orais a termo. É importante também que se observe uma lógica mínima que garanta o seu sucesso, com uma fase de instauração, outra probatória e uma conclusiva.

$O$ arquivamento da investigação deve ser submetido ao órgão superior do Ministério Público, o Conselho Superior, no caso dos Ministérios Públicos, dos Estados, e as Câmaras de Coordenação e Revisão, no caso do Ministério Público Federal, que pode ratificá-lo ou não. Neste último caso, outro membro do Ministério Público adotará as medidas determinadas pelo órgão revisor, em homenagem ao princípio da independência funcional. A legislação admite recurso por parte de qualquer interessado contra a deliberação de arquivamento dirigido ao órgão superior, o que enseja o exercício do controle social da atividade do Ministério Público.

O princípio da publicidade se aplica ao inquérito civil com as ressalvas ordinárias da legislação nacional, ou seja, não podem ser divulgadas as informações cujo sigilo deva ser mantido para proteger o interesse público e o direito à intimidade e à vida privada das pessoas. No primeiro caso, o

(28) Cf. Lei Complementar n. 75/93, art. 8, inciso III: "No exercício de suas funções o Ministério Público poderá: III - requisitar da Administração Pública serviços temporários de seus servidores e meios materiais necessários para a realização de atividades específicas." 
interesse público é uma noção aberta que pode justificar, em múltiplas situações, o sigilo da investigação, até mesmo para resguardar a eficácia de seus resultados. A segunda hipótese ocorre quando a divulgação de um dado apurado em sigilo represente afronta ao direito, também de dignidade constitucional, da proteção da imagem, da honra e da intimidade das pessoas ${ }^{(29)}$.

Em matéria do direito à saúde há o sigilo profissional dos médicos sobre as informações constantes em prontuários, que pode ser quebrado quando autorizado pelo paciente, uma vez que tal sigilo existe em homenagem à privacidade do doente, ou através do recurso aos médicos auditores que podem identificar qual a informação relevante para a investigação, por exemplo, a adequação do tratamento para a hipótese diagnosticada, sem que outros dados sejam divulgados.

O inquérito civil é um verdadeiro "instrumento de cidadania ${ }^{(30) "}$ e, muitas vezes, a sua própria instauração favorece a reparação à lesão ao direito à saúde. Ademais, o seu adequado manejo evita a propositura de lides temerárias, além de ser palco de alternativas à movimentação da máquina jurisdicional, posto que importantes medidas extrajudiciais de composição do conflito coletivo são adotadas nos autos do inquérito, como demonstraremos a seguir.

A recomendação é um instrumento previsto na Lei Complementar n. $75 / 93^{(31)}$ e na Lei Orgânica Nacional do Ministério Público dos Estados ${ }^{(32)}$. Consiste, como sugere o seu nome, na possibilidade do Ministério Público recomendar aos responsáveis a adoção de medidas que possam favorecer a adequada prestação de serviços públicos de saúde ou o respeito ao direito à saúde. É uma tarefa típica de ombudsman ${ }^{(33)}$.

(29) Protegido no art. 5, inciso $X$ : são invioláveis a intimidade, a vida privada, a honra e a imagem das pessoas, assegurado o direito à indenização pelo dano material ou moral decorrente de sua violação.

(30) Nesse sentido CAMARGO, Antônio Augusto Mello de. Inquérito civil público: dez anos de um instrumento de cidadania. In: MILARÉ, Edis (Coord.). Ação civil pública (Lei n. 7.347/85 - reminiscências e reflexões após dez anos de aplicação). São Paulo: Ed. Revista dos Tribunais, 1995. p. 62-69.

(31) Art. 6 da Lei Complementar n. 75/93, XX - expedir recomendações, visando à melhoria dos serviços públicos e de relevância pública, bem como ao respeito, aos interesses, direitos e bens cuja defesa lhe cabe promover, fixando prazo razoável para a adoção das providências cabíveis.

(32) Art. 27, parágrafo único, IV - promover audiências públicas e emitir relatórios, anual ou especiais, e recomendações dirigidas aos órgãos e entidades mencionadas no caput deste artigo, requisitando ao destinatário sua divulgação adequada e imediata, assim como resposta por escrito.

(33) Cf. Celso Barroso Leite: "As conclusões a que ele chega com relação a reclamações investigadas, casos apurados por sua própria iniciativa, fatos verificados por ocasião de visitas de inspeção, e assim por diante, são transmitidas às repartições 
A recomendação não obriga o recomendado a cumprir os seus termos; mas, serve como advertência a respeito das sanções cabíveis pela sua inobservância. É importante que este instrumento seja devidamente justificado, de modo a que possa convencer o recomendado de sua justeza. Em regra, é expedida nos autos do inquérito após a sua instrução, como forma de evitar a propositura da medida judicial e quando não seja caso de ajustamento de conduta; contudo, nada impede que seja feita fora de uma investiga-

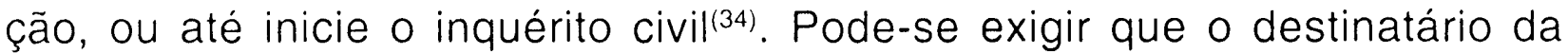
recomendação promova a sua publicação, assim como apresente resposta por escrito ao Ministério Público, informando sobre o cumprimento da mesma. O Ministério Público também pode dar publicidade à recomendação(35).

É uma prática cada vez mais utilizada pelos membros do Ministério Público e com uma eficácia bastante razoável. Podemos citar três exemplos de recomendações bem-sucedidas em matéria de saúde: a) a Recomendação n. 18/99/SP, que protestava pelo empenho do Ministério da Saúde em evitar a falta de medicamentos para as pessoas portadoras do vírus HIV e redundou no pedido de suplementação de verbas públicas para o programa(36); b) a Recomendação da PR/BA à Superintendência do Banco do Brasil no Estado da Bahia orientando a não realização de determinadas movimentações nas contas bancárias dos Fundos Municipais de Saúde sem o pedido por escrito do titular, para que as responsabilidades sobre a gestão da conta pudessem ser devidamente apuradas, o que tem facilitado a apuração de fraudes envolvendo esses recursos públicos ${ }^{(37)}$; c) a Recomendação n. 002/ 03-AM-PRDF determinando a adequação da proposta orçamentária da União para excluir do cômputo como verba de saúde dos recursos destinados ao Fundo de combate e erradicação da pobreza ${ }^{(38)}$.

interessadas sob a forma de criticas, censuras ou recomendações. Em qualquer hipótese, seus pronunciamentos não têm cunho coercitivo, mas sobretudo efeito moral - de resto mais forte do que poderia parecer. Não raro suas manifestações, em vez de se limitarem aos casos concretos que as motivaram, cogitam de medidas de caráter geral: alterações de normas, simplificação de rotinas, abrandamento de critérios, etc." Op. cit. p. 62.

(34) Nesse sentido ROTHENBURG, Walter Claudius. "Recomendação: publicidade e publicação". Tese apresentada no XVI Encontro Nacional dos Procuradores da República. Caderno de Teses. ANPR. Rio de Janeiro 28/10 a 2.11.99. pp.19/22.

(35) Segundo Rothenburg: "O Procurador da República responsável pela recomendação tem legitimidade para avaliar acerca da publicidade e publicação. Não cabe à Câmara de Coordenação e Revisão ou ao procurador Federal dos Direitos do Cidadão recusar-se a fazer publicá-la." op., cit. p. 22.

(36) Rothenburg, op. cit. p. 20.

(37) Recomendação expedida no Procedimento Administrativo MPF/PR/BA n. 08104.000467/98-53.

(38) Essa recomendação foi expedida pelo então Procurador Geral da República, Dr. Cláudio Lemos Fonteles, a pedido dos colegas do Distrito Federal, e conseguiu rever- 
- Em virtude da própria natureza da recomendação, seu espectro de abrangência é amplíssimo. Pode se recomendar a adoção de medidas que estão sob o juízo discricionário da Administração Pública, ou medidas que só podem ser determinadas com força de executoriedade pelo Poder Judiciário. O recomendado pode ou não acatar a medida. Essa, em muitos casos, é a vantagem do instituto lograr demonstrar ao responsável pela conduta como pode evitar a continuidade de uma prática indevida ou adequá-la aos ditames legais. No caso do recomendado reputar inadmissível o conteúdo da orientação, basta não observá-la e apostar no insucesso de qualquer iniciativa judicial. Caso seja instado a fazê-lo, deve declinar, por escrito, ao membro do Ministério Público que expediu a recomendação os motivos que levaram à inobservância da mesma. Em relação à medida judicial, a reclamação representa todas as vantagens inerentes a uma solução extrajudicial de conflito: pouco custo e rapidez.

A audiência pública é um importante instrumento do Estado Democrático de Direito, construído a partir da extensão do princípio da audiência individual(39), ou seja: para a solução de um litígio deve-se sempre tentar ouvir o indivíduo diretamente interessado, essa mesma lógica é utilizada para a solução de conflitos que envolvam muitas pessoas, permitindo que este público conheça e se manifeste sobre as medidas que the dizem respeito. Geralmente, são realizadas para as audiências públicas, tanto na esfera administrativa quanto legislativa, para se consultar a comunidade sobre a adoção de medidas de caráter geral ou antes de aprovar projetos de grande importância ou de expressivo impacto social ao meio ambiente ou à comunidade.

Segundo Agustín Gordillo, a audiência pública tem as seguintes funções: a) permite ao administrado verificar objetivamente a razoabilidade da medida administrativa; b) é um mecanismo idôneo de formação de consenso da opinião pública a respeito da juridicidade e conveniência de uma atuação do Estado; c) garante a transparência dos procedimentos decisórios do Estado; d) é um elemento de democratização do exercício do poder; e) é um modo de participação cidadã na gestão da coisa pública, concretizando os princípios políticos e constitucionais de democracia participativa; f) tem uma importante função preventiva, pois pode evitar os prejuizos causados por uma intervenção administrativa inadequada ${ }^{(40)}$.

O Ministério Público pode participar de audiência pública promovida por outros órgãos públicos quando a temática da audiência seja relevante

ter o intento do governo de incluir nas verbas da saúde os valores destinados ao Programa Fome Zero, o que redundaria em redução de até $R \$ 1$ bilhão de Reais nos valores destinados às ações e programas de saúde.

(39) GORDILLO, Agustín. Tratado de derecho administrativo. la defensa del usuario y de administrado. 3. ed. Buenos Aires: Fundación de Derecho Administrativo, 1998. t. 2, p. XI-2.

(40) Op. cit. p. XI-9. 
para o exercício do seu ofício, ou mesmo promover a realização de audiência pública para ensejar a participação da coletividade no curso de uma investigação que esteja conduzindo.

O termo de ajustamento de conduta é um importante instrumento de atuação do Ministério Público, pois permite a adequação da conduta do investigado às exigências legais, com a formação de um título executivo extrajudicial(41). A legislação permite que o Ministério Público e outros órgãos públicos legitimados possam negociar prazos e condições de atendimento das obrigações previstas em lei, sendo que esse compromisso é uma alternativa à demanda judicial. Em pesquisa realizada no periodo de 1999 a 2004, do total de 246 ajustes celebrados pelo Ministério Público Federal, examinados 20 tratavam do direito à saúde, por exemplo, com obrigações sobre reabertura de unidades de serviços e regularização de serviços, implementação de programa de vigilância sanitária, formação técnicos em enfermagem, melhorias de saneamento básico e financiamento de hospital. ${ }^{(42)}$

Quando o exercício das atividades extrajudiciais do Ministério Público não tem êxito, a instituição pode se valer de seus tradicionais poderes de pleitear perante o Poder Judiciário o cumprimento das medidas que reputar relevantes para a concretização do direito à saúde, através do manejo das ações coletivas. Apenas em situações singulares o Ministério Público pode atuar judicialmente em favor do indivíduo, quando se tratam de direitos indisponiveis de pessoas que gozam de proteção jurídica especial como os portadores de deficiência, as crianças e os idosos em situação econômica precária. Em relação ao cidadão em geral, o Ministério Público no exercício de sua atividade de ombudsman pode orientá-lo sobre a forma de exercer os seus direitos.

\section{PARALELO ENTRE O MINISTÉRIO PÚBLICO E O OMBUDSMAN DA SAÚDE NORUEGUÊS}

Apresentado um panorama de como atua o Ministério Público em matéria de saúde no Brasil, poderemos traçar um breve paralelo com a experiência norueguesa(43).

Em primeiro lugar, há diferenças significativas na própria conformação institucional de cada órgão que atua em favor do direito à saúde nos dois

(41) Lei n. 7.347/85 - Art. 5, $\S 6^{\circ}$ Os órgãos públicos legitimados poderão tomar dos interessados compromisso de ajustamento de sua conduta às exigências legais, mediante cominações, que terá eficácia de título executivo extrajudicial.

(42) A pesquisa foi patrocinada pela Escola Superior do Ministério Público da União. (43) As informações sobre o ombudsman da saúde foram retiradas do texto do professor Olav Molven. The patiente ombudsman - the norwegian experience. 
países examinados. Os atuais dezenove ombudsmen da saúde noruegueses são nomeados pelo Ministro da Saúde para atuarem em uma determinada região. No Brasil, os integrantes do Ministério Público são nomeados pelo Chefe da própria instituição, após a aprovação em concurso público, acessivel apenas a bacharéis de Direito, e atuam na circunscrição territorial correspondente a uma comarca judicial ou a uma seção judiciária, caso seja respectivamente, o Ministério Público Estadual ou Federal. Embora o número de integrantes do Ministério Público seja muito maior - apenas o Estado de São Paulo tem 1.738 membros e o Ministério Público Federal, 825 aqueles que se dedicam exclusivamente ao ofício da saúde são no máximo 100 integrantes. De qualquer maneira, a temática da saúde vem se tornando cada vez mais presente nas atividades do Ministério Público, havendo, inclusive, uma Associação do Ministério Público de Defesa da Saúde AMPASA ${ }^{(44)}$.

Apesar do vínculo mais forte com o Poder Executivo, posto que são nomeados pelo Ministro da Saúde, na avaliação do professor Olav Molven o ombudsman do paciente na Noruega é totalmente independente dos interesses do Ministério e dos dirigentes dos hospitais públicos. No Brasil, a independência do Ministério Público é garantida por salvaguardas institucionais como autonomia orçamentária e administrativa e as prerrogativas dos membros da carreira, que gozam de irredutibilidade de vencimentos, vitaliciedade (só perdem a função mediante ação judicial) e inamoivibilidade (só podem ser removidos desses postos de atuação se o interesse público determinar por decisão de maioria absoluta do Conselho Superior).

Ao contrário do ombudsman da saúde, o Ministério Público no Brasil exerce outras funções além da defesa do direito à saúde, como visto, embora em algumas localidades existam membros da instituição que oficiam com exclusividade na matéria, como já mencionado. A inexistência da especialização limita a eficácia e sua atuação. O primeiro aspecto digno de nota é a necessidade do estudo atento da legislação que rege a matéria, bastante vasta e diversificada, como o capítulo da Constituição dedicado à saúde, todas as Leis federais que versam sobre a matéria, especialmente $8.080 / 90$, 8.142/90 e 9.452/97, as normas do Ministério da Saúde, como a NOB (norma básica) n. 1/2000, as portarias do Ministro, as resoluções do Conselho Nacional de Saúde, as recomendações das Conferências Federal e Estaduais de Saúde etc.

Ademais, não se pode perder de vista que, independentemente da ótica em que se analisa a demanda referente à saúde apresentada ao Ministério Público, as questões se apresentam dentro de um dado contexto, cuja lógica deve ser compreendida. Por exemplo, no caso de denúncias contra instituições particulares ou públicas que integram a rede do SUS referentes

(44) O site da AMPASA é <http://www.ampasa.org.br/index.jsp>. 
à violação ao princípio da gratuidade, à dupla cobrança, à cobrança de atendimentos inexistentes etc., estão envolvidos valores diminutos; mas, se é uma prática constante da instituição pode se revelar extremamente lucrativa e, evidentemente, o conjunto de todas as fraudes é bastante prejudicial ao sistema. Só uma visão holística permite identificar esse fenômeno. Por outro lado, existem situações em que a solução mais extremada de interdição do hospital ou de seu descredenciamento ao SUS pode vir a ser mais lesiva à comunidade de usuários, notadamente quando na localidade só existe um prestador do serviço de saúde. Essa perspectiva, às vezes, somente é possível quando há uma efetiva preocupação do representante do Ministério Público com os objetivos de sua atuação, o que certamente é favorecido quando há uma dedicação a estes temas.

Em todas as áreas de atuação do Ministério Público no ofício de saúde, é fundamental que haja um contato permanente com os diversos atores políticos que participam da rede de relações que envolvem a área. Sem essa interlocução, a atuação pode ficar seriamente comprometida. Deve haver um constante diálogo com os órgãos representantes das classes de profissionais de saúde quer sejam corporativos - como os Sindicatos e Associações de profissionais - de fiscalização profissional - como os Conselhos de Medicina, Enfermagem, Psicologia, Farmácia - ou técnicos, como as Sociedades médicas, todos têm muito a contribuir para o trabalho. Do mesmo modo conhecer os principais gestores públicos, como os Secretários-executivos do Ministério da Saúde, as Secretarias de Saúde dos Estados e dos Municípios, as Coordenações das auditorias, principalmente federal e estaduais, as Coordenações dos Serviços de Vigilância Sanitária, os diretores dos hospitais mais importantes etc., é bastante relevante na condução das investigações. Também é favorável uma interação com as ouvidorias de saúde da União, dos Estados e Municípios e dos hospitais, para que se possa ter pleno conhecimento das condições de atendimento de saúde dos cidadãos em dada localidade. Não se pode olvidar, outrossim, as associações de usuários de saúde que, quase sempre, são parceiras indispensáveis para que as atribuições nessa área sejam conhecidas e para que se possa estabelecer, com maior acerto, as prioridades da atuação.

No sistema norueguês, embora atue exclusivamente como ombudsman da saúde, sua função é mais limitada porque somente abrange casos relacionados à prestação de saúde especializada (public secondary health care) e seus poderes não abrangem decisões vinculantes a terceiros, mas tão-somente recomendações. O Ministério Público, ao revés, pode atuar administrativamente em qualquer questão relacionada aos direitos dos pacientes, pode postular em juizo em favor dos interesses da coletividade e de alguns indivíduos com proteção especial e pode celebrar acordos vinculantes para as partes (termo de ajustamento de conduta). 
O ombudsman da saúde pode deliberar sobre as prioridades de sua atuação em cada caso que lhe é apresentado, enquanto no Brasil ainda há controvérsia sobre a possibilidade do Ministério Público deixar de atuar quando for caso de sua atribuição. De qualquer sorte, tem se exigido do órgão a definição de metas e prioridades para que atue de forma mais eficiente e permita um controle social do exercício de suas atribuições.

No Brasil, a defesa do direito da saúde através do Ministério Público somente pode ser feita por graduado em Direito, ao contrário do ombudsman do paciente da Noruega que, ainda que minoritariamente, conta com pessoas com formação na área de saúde, embora com treino legal. Obviamente que o melhor exercício da defesa do direito à saúde pressupõe um diálogo constante daqueles que têm formação jurídica com os profissionais de saúde e, na prática, é isto que acontece, não somente porque o Ministério Público conta com equipe de profissionais de outras formações, como também seu relacionamento é estreito com universidades e sociedades técnicas que atuam como peritos de saúde.

Algumas similitudes existem entre as duas instituições, como, por exemplo, o fato de possuírem os mesmos poderes para instruir as suas investigações, que se processam sem grandes formalismos, ensejarem acesso gratuito dos seus serviços ao cidadão e a possibilidade de orientação legal àquele que se vê em um conflito de saúde.

\section{CONSIDERAÇÕES FINAIS}

Reconhecer a proteção da saúde como um direito humano é fundamental para que possamos travar um diálogo em países de realidades tão distintas. Por mais que nos cause estranheza as paisagens e os personagens de Lars Saabye Christensen ${ }^{(45)}$, interessante é perceber que o controle da eficiência daqueles que se ocupam com a saúde da população na Noruega pode nos inspirar naqueles aspectos que se revelam mais simples: a dedicação exclusiva aos assuntos da saúde, uma aproximação, inclusive física, dos usuários dos serviços e o compromisso das autoridades públicas com a promoção do interesse público. Não existe uma fórmula mágica que vai transformar o padrão de nosso serviço de saúde e a sua capacidade de atendimento universal, mas a lição norueguesa é que podemos construir, dentro de nossas possibilidades e necessidades, uma condição mais favorável para que essas metas sejam cotidianamente honradas.

Ademais, a maior eficácia do Ministério Público na tutela do direito à saúde, e das outras ouvidorias acessíveis ao paciente no Brasil, está inti-

(45) Vide O MEIO Irmão. Rio de Janeiro: Objetiva, 2005. 
mamente relacionada com a percepção da saúde como um direito pelo cidadão brasileiro. No Brasil, o acesso à justiça ainda precisa superar a primeira barreira que é todo cidadão se vislumbrar como um sujeito de direitos. Esta é uma revolução que deve ser empreendida e que vai muito além da concepção de instituições de controle do agir administrativo, porque requer que as pessoas assumam o controle do seu destino pessoal e o de sua comunidade.

\section{REFERENNCIAS}

AMPASA. Disponivel em: <http://www.ampasa.org.br/index.jsp>.

CAMARGO, Antônio Augusto Mello de. Inquérito civil público: dez anos de um instrumento de cidadania. In: MILARÉ, Edis (Coord.). Ação civil pública (Lei n. 7347/85 - reminiscências e reflexões após dez anos de aplicação). São Paulo: Ed. Revista dos Tribunais, 1995. p. 62-69.

COMPARATO, Fábio Konder. Segurança e democracia. In: Direito, cidadania e participação. São Paulo: T. A. Queiroz, 1981.

DICIONÁRIO de Política. Brasília: Ed. da UNB, 1991, v. 2.

GORDILLO, Agustín. Tratado de derecho administrativo: la defensa del usuario y de administrado. 3. ed. Buenos Aires: Fundación de derecho administrativo, 1998, t. 2.

LEITE, Celso Barroso. Ombusdman. Corregedor administrativo. A instituição escandinava que o mundo vem adotando. Rio de Janeiro: Zahar, 1975. LOPES, Júlio Aurélio Vianna. "Funções do Estado, 'Alicerces da sociedade', $e$ 'Condições da vida'”. Rio de Janeiro: Lumen Juris, 2000.

LYRA, Roberto. Visão social do direito. Rio de Janeiro: Ed. Rio, 1976.

O MEIO Irmão. Rio de Janeiro: Objetiva, 2005.

MUDA Brasil. Uma Constituição para o desenvolvimento democrático. São Paulo: Brasiliense, 1987.

OLIVEIRA FILHO, João de. O ombusdman, instrumento de defesa dos direitos humanos nas democracias modernas. Revista dos Tribunais, São Paulo, v. 497, mar. 1977.

RODRIGUES, Geisa de Assis. Ação civil pública e termo de ajustamento de conduta. Rio de Janeiro: Forense, 2006.

ROTHENBURG, Walter Claudius. Recomendação: publicidade e publicação. Tese apresentada no XVI Encontro Nacional dos Procuradores da República. Caderno de Teses. ANPR. Rio de Janeiro 28.10 a 2.11.99.

TÁCITO, Caio. Ombusdman: o defensor do povo. Revista de Direito Administrativo, Rio de Janeiro, n. 171, p. 15-26, jan./mar. 1988. 